Henao Alvarez, O., Ramírez Salazar, D. A., Villa Lombana, V., Soto Ossa, P. A., y Morales Benjumea, J. (enero-abril, 2022). La enseñanza virtual en el contexto de la cultura académica universitaria: Una aproximación a los procesos de tutoría y acompañamiento. Revista Virtual

Universidad Católica del Norte, (65), 31-65. https://www.doi.org/10.35575/rvucn.n65a3

\title{
La enseñanza virtual en el contexto de la cultura académica universitaria: Una aproximación a los procesos de tutoría y acompañamiento
}

Virtual teaching in the context of university academic culture: An approach to the tutoring and accompaniment Processes

\section{Octavio Henao Alvarez}

Doctor en Educación

Facultad de Educación, Universidad de Antioquia

Medellín, Colombia

octavio.heano@udea.edu.co

Orcid: https://orcid.org/0000-0001-8327-4717

CvLAC:

http://scienti.colciencias.gov.co:8081/cvlac/visualizador/generarCurriculoCv.do?cod_rh=0000060062

\section{Doris Adriana Ramírez Salazar}

Doctora en Educación

Facultad de Educación, Universidad de Antioquia

Medellín, Colombia

doris.ramirez@udea.edu.co

Orcid: https://orcid.org/0000-0002-2728-7297

CvLAC:

http://scienti.colciencias.gov.co:8081/cvlac/visualizador/generarCurriculoCv.do?cod_rh=0000060070

\section{Vanessa del Carmen Villa Lombana}

Magíster en Educación

Facultad de Educación, Universidad de Antioquia

Medellín, Colombia

delcarmen.villa@udea.edu.co

Orcid: https://orcid.org/0000-0002-3546-7634

CvLAC:

https://scienti.minciencias.gov.co/cvlac/visualizador/generarCurriculoCv.do?cod_rh=0001416082 


\author{
Paola Andrea Soto Ossa \\ Magíster en Educación \\ Facultad de Educación, Universidad de Antioquia \\ Medellín, Colombia \\ pandrea.soto@udea.edu.co \\ Orcid: https://orcid.org/0000-0003-1520-4201 \\ CvLAC: \\ https://scienti.minciencias.gov.co/cvlac/visualizador/generarCurriculoCv.do?cod_rh=0001770355 \\ Jasmin Morales Benjumea \\ Estudiante de Maestría en Educación \\ Facultad de Educación, Universidad de Antioquia \\ Medellín, Colombia \\ jasmin.moralesb@udea.edu.co \\ Orcid: https://orcid.org/0000-0002-0038-5196 \\ CvLAC: \\ https://scienti.minciencias.gov.co/cvlac/visualizador/generarCurriculoCv.do?cod_rh=0001774620
}

Recibido: 16 de febrero de 2021

Evaluado: 17 de agosto de 2021

Aprobado: 17 de diciembre de 2021

Tipo de artículo: Investigación Científica y Tecnológica

\title{
Resumen
}

Este artículo describe una investigación de corte cualitativo, que se desarrolló a través de cuatro fases: exploración teórica, construcción de la propuesta de formación, experimentación de la propuesta de formación y el proceso de análisis de los datos, y buscaba contribuir a la cualificación de la educación en línea y al reconocimiento de elementos conceptuales, metodológicos y técnicos involucrados en los procesos de enseñanza universitaria. Los principales hallazgos coinciden en valorar la presencia docente, la comunicación y la interacción, el trabajo en equipo, las comunidades de aprendizaje, la autonomía y el acompañamiento tutorial, como elementos primordiales en la tutoría virtual. Se identificaron, además, las percepciones de los participantes, en relación con lo que significaron las prácticas de enseñanza del tutor. Finalmente, las conclusiones sugieren la relevancia de la tutoría, como atributo de la enseñanza virtual, asociada a la planificación del proceso formativo, desde el reconocimiento de formas de comunicación e interacción propias del ciberespacio; posibilitando de tal forma la consolidación de entornos de aprendizaje. 
Palabras clave: Acompañamiento tutorial virtual; Educación virtual; Enseñanza virtual; Tutor virtual.

\begin{abstract}
This article describes a qualitative research, which was developed through four phases: theoretical exploration, construction of the training proposal, experimentation of the training proposal, and the data analysis process, and sought to contribute to the qualification of online education, and the recognition of conceptual, methodological and technical elements involved in university teaching processes. The main findings coincide in valuing the teaching presence, communication and interaction, teamwork, learning communities, autonomy and tutorial support, as essential elements in virtual tutoring. The perceptions of the participants in relation to what the tutor's teaching practices meant are also identified. Finally, the conclusions suggest the relevance of tutoring, as an attribute of virtual teaching, associated with the planning of the training process, from the recognition of forms of communication and interaction typical of cyberspace; thus enabling the consolidation of learning environments.
\end{abstract}

Keywords: Online tutoring; Virtual education; Online teaching; Virtual tutor.

\title{
Introducción
}

La presencia de las tecnologías digitales en el campo educativo ha generado una serie de desafíos pedagógicos para los docentes, en tanto educar en el contexto de la virtualidad implica pensar otros modos de relacionamiento con los estudiantes (Díez-Echavarría et al., 2018; ValenciaArias et al., 2018). En este escenario, el tutor virtual no solo debe contar con una serie de habilidades técnicas, sino que además debe disponer de un saber pedagógico disciplinar -un saber que se produce, fundamenta y transmite en el marco de la pedagogía como disciplina-. El saber pedagógico disciplinar es el saber logrado mediante la actividad investigativa y la reflexión (Runge et al., 2018), y es el que le permite al docente plantear estrategias metodológicas y gestionar un entorno de aprendizaje que favorezca en los estudiantes el pensamiento crítico y la capacidad para 


\section{La enseñanza virtual | Revista Virtual} Universidad Católica del Norte, 65, 31-65

ISSN: 0124-5821 (En línea)

aprender de forma autónoma y colaborativa. El ejercicio de la tutoría debe partir del reconocimiento de estrategias efectivas para la enseñanza en la virtualidad, que, desde la sincronía y asincronía, contemplen la relación entre medios, mediaciones y contextos.

Los procesos de enseñanza y aprendizaje en los escenarios virtuales implican un ejercicio distinto en relación con la presencialidad, pues los docentes deben preparar las clases, pensar los recursos y diseñar las actividades para que los estudiantes construyan sus propias significaciones. Mientras que los estudiantes desarrollan más trabajo independiente, en tanto estos escenarios les demandan mayor autonomía. En la enseñanza virtual el tutor se asume como un mediador y es el responsable de pensar asuntos relacionados con las formas de participación de los estudiantes. El tutor virtual es quien propicia las interacciones, la comunicación y despliega actividades de enseñanza, atendiendo a aspectos técnicos, metodológicos, disciplinares, conceptuales y afectivos.

El equipo investigador buscó aproximarse a los procesos de tutoría y acompañamiento en los escenarios virtuales, por ello desarrolló una investigación denominada Formación de tutores virtuales: una estrategia para mejorar la eficiencia y calidad de la educación en línea, que buscaba ofrecer elementos conceptuales, metodológicos y técnicos para el fortalecimiento de las prácticas de enseñanza y aprendizaje en el contexto de la virtualidad. En tal sentido, los autores entienden que la medida de la calidad y eficiencia de la enseñanza virtual es el aprendizaje logrado de quienes utilizan sus recursos y estrategias; por ello, la educación debe estimular un aprendizaje significativo con el objetivo de mejorar la calidad de la vida de quienes aprenden. Es preciso, entonces, entender la calidad de la educación virtual como un asunto asociado con el sistema social y de valores, que se transmite por medio de herramientas de comunicación, los contenidos y las estrategias didácticas en un espacio de formación. De ahí que sea importante dar prioridad a la configuración de comunidades virtuales como una nueva forma de configurar procesos de educación en la virtualidad (Salinas, 2005).

Como fruto de este proceso se diseñó y experimentó una estrategia de formación para tutores virtuales, denominada Educar en la virtualidad: una enseñanza que deja huella. La investigación se desarrolló en la ciudad de Medellín y contó con la participación de veintidós profesores universitarios - diecisiete mujeres y cinco hombres-. Quince de ellos pertenecían al área de las ciencias sociales, cinco al área de la salud y dos al área de las ciencias exactas. A través del 


\section{La enseñanza virtual | Revista Virtual} Universidad Católica del Norte, 65, 31-65

ISSN: 0124-5821 (En línea)

diseño metodológico se buscó responder a asuntos relacionados con la formación didáctica y pedagógica del docente, y los roles y funciones del tutor virtual.

A continuación, se presentan algunas de las investigaciones más relevantes asociadas a los procesos de tutoría y acompañamiento en los escenarios virtuales:

En primera instancia, Castañeda et al. (2017) presentan una experiencia de diseño, implementación y evaluación de un curso virtual enfocado al desarrollo de las competencias para gestionar e impartir cursos en línea. El curso consta de 10 módulos -60 horas- configurados como unidades de aprendizaje, basadas en tareas individuales y grupales, utilizando diferentes herramientas -tableros colaborativos, videoconferencias, etc-. En esta misma perspectiva, Rapp \& Gülbahar (2016) desarrollaron un proyecto denominado e-Tutor para formar a tutores virtuales mediante una metodología en línea. En el marco del proyecto se planteó un curso educativo abierto para la formación de tutores; este proceso formativo se desarrolló en Moodle y se aplicó a más de 900 profesionales en tres idiomas distintos. El programa e-Tutor consta de 14 módulos, en los cuales se utilizó una amplia gama de materiales para garantizar la participación de los estudiantes.

Así mismo, los investigadores Tejada y Pozos (2018) mostraron que las tecnologías de la información y la comunicación coadyuvan la configuración del perfil del docente universitario, en clave de nuevas funciones, roles y habilidades profesionales en el contexto de la virtualidad.

De igual modo, Puerta Gil y Mosquera Perea (2020), en el contexto de la Fundación Universitaria Católica del Norte, desarrollaron el microcurso Enseñar en la virtualidad: competencias digitales para docentes en AVA, con más de cuatro mil maestros y maestras de instituciones de educación básica y educación superior de varios países latinoamericanos, incluido Colombia. Este microcurso se realizó de modo virtual y tuvo como finalidad ofrecer herramientas pedagógicas a los docentes para trabajar con sus estudiantes en ambientes virtuales de aprendizaje. El microcurso fue valorado positivamente por los docentes, quienes manifestaron que esta experiencia formativa contribuyó en la adquisición y fortalecimiento de aprendizajes pedagógicos, didácticos y comunicativos desde la virtualidad.

Finalmente, Morado y Ocampo (2019) diseñaron e implementaron una propuesta de formación con 149 maestros. Se realizaron 4 encuentros semanales con el fin de acompañarlos en la construcción de un espacio virtual de aprendizaje, desde lo teórico y lo metodológico; además, se generaron espacios de discusión en torno a la práctica docente. Este proceso favoreció la 


\section{La enseñanza virtual | Revista Virtual} Universidad Católica del Norte, 65, 31-65

ISSN: 0124-5821 (En línea)

creatividad en la construcción de EVA y un cambio de perspectiva sobre los espacios virtuales, en tanto se identificó que la tecnología facilita los procesos de aprendizaje de los estudiantes.

A partir de lo anterior, se evidencia la importancia de contar con estrategias pedagógicas y didácticas que respondan a las necesidades de formación de los docentes universitarios en el contexto de la virtualidad; de modo que se contribuya al mejoramiento de la calidad y permanencia estudiantil en esta modalidad educativa. A lo largo del artículo se hace referencia a las potencialidades que tienen las tecnologías de la información y la comunicación -TIC- para apoyar la enseñanza y propiciar diversas formas de interacción y comunicación con los estudiantes; igualmente, se hace referencia a una comparación constante entre el desarrollo de procesos de formación a través de internet y el desarrollo de las tecnologías. En tal sentido, se entiende la educación virtual o educación en línea como aquella que se promueve en un entorno de aprendizaje, mediada por TIC y que está centrada en los estudiantes, quienes participan en la contextualización del aprendizaje, y asumen independencia y autonomía en el marco de un proceso de aprendizaje social que da especial relevancia a las experiencias que posibilitan la colaboración y la retroalimentación del profesor (Gros, 2011).

\section{Marco Teórico}

Las TIC tienen un lugar fundamental en la configuración de las sociedades modernas y en los procesos de formación que se despliegan en el ámbito universitario Las tecnologías digitales en el contexto educativo ofrecen posibilidades y, a su vez, plantean retos y desafíos (MosqueraGonzález et al., 2021). Por ejemplo, la educación a distancia ha permitido romper con las barreras espaciales y temporales tradicionales de los procesos formativos (Gabarda et al., 2019), en tanto muchos estudiantes que se encuentran territorialmente lejos, y a quienes no les es posible acceder de manera física a la institución, han podido formarse "utilizando para ello diferentes medios impresos, analógicos o digitales, de acuerdo a la época-" (Yong et al., 2017, p. 83). Estas tecnologías digitales también interpelan, retan y desafían a los maestros todo el tiempo, ¿cómo usarlas?, ¿dónde?, ¿cuándo?, ¿con quiénes?, ¿cuáles son los roles de los maestros y de los estudiantes en el contexto de la educación virtual? En consecuencia, la configuración de propuestas didácticas en estos escenarios virtuales demanda de una posición reflexiva por parte de los 


\section{La enseñanza virtual | Revista Virtual} Universidad Católica del Norte, 65, 31-65

ISSN: 0124-5821 (En línea)

docentes y les plantean "desafíos pedagógicos que pre-existen y sobreviven a la sucesiva implementación de estas tecnologías" (Spiegel, 2020, p. 22).

Los entornos virtuales de aprendizaje (EVA) se asumen como recursos digitales que posibilitan la gestión del conocimiento y el desarrollo de competencias en los estudiantes (EdelNavarro, 2010). Los EVA son una expresión muy importante del impacto que han tenido las TIC en la educación de niños, niñas, jóvenes y adultos, en tanto facilitan las condiciones socioespaciales y, a su vez, se favorece la construcción de conocimiento de forma colaborativa, a partir de las interacciones e intercambios que se generan entre el maestro y los participantes (Gabarda et al., 2019; Yong y Bedoya, 2016). En estos escenarios el tutor promueve diferentes prácticas con sus estudiantes, tales como el diálogo, la participación y la autonomía (Campisi, 2018); sin embargo, la utilización de los EVA requiere de una reflexión profunda por parte del docente; no se trata de utilizarlos por utilizarlos, sino que es necesario contextualizar su uso y pensar el sentido que estos tienen en el marco de los procesos formativos (Segura-Robles y Gallardo-Vigil, 2013).

El docente tiene un lugar fundamental en los EVA y, por ende, en la formación de los sujetos (Gerrard, 2004; Llorente, 2006; McPherson \& Nunes, 2004; Mishra \& Juwah, 2006; Quezada, 2017; Seoane, 2014; Silva, 2010; Yong y Bedoya, 2016). Tal y como lo precisan Yong y Bedoya (2016), "el docente se convierte en tutor, facilitador del aprendizaje, fomentando y respetando el aprendizaje autónomo en el estudiante" (p. 15). El tutor es quien orienta, guía y acompaña al estudiante para que logre alcanzar los objetivos de formación (Quezada, 2017; Yong y Bedoya, 2016). Es a partir de los procesos de tutorías -sistemáticas, intencionales y planificadasque es posible "individualizar, supervisar y evaluar el trabajo autónomo del estudiante" (Martínez et al., 20114, p. 271).

Este proceso de tutoría virtual le implica al maestro asumir una serie de retos antes, durante y después del proceso de enseñanza. Por ejemplo, conocer y dominar las plataformas tecnológicas que se utilizan para llevar a cabo los procesos de formación, atender a cada participante en su singularidad, generar espacios de interlocución permanentes con los estudiantes, favorecer procesos de aprendizaje que sean significativos e impacten las realidades de los participantes, y propiciar la construcción colectiva del conocimiento (Chacón, 2018). 
La relación entre tutor y estudiante debe volverse lo más cercana posible. Además, que esta relación uno a uno, casi en forma privada, crea un ambiente de intimidad y confianza que permite que afloren muchas inquietudes, que en otros espacios sería casi imposible. (Chacón, 2018, p. 4)

En esta investigación se comprende el aprendizaje como un proceso de construcción social, lo cual implica que el estudiante participe en un entorno en el que se le ofrezcan recursos, ambientes, puentes de comunicación, sentidos y lenguajes que le permitan contribuir y participar en esa construcción social. En los entornos virtuales es de gran importancia el aprendizaje colaborativo, dada la naturaleza social de los seres humanos y la necesidad de interactuar y reconocer al otro en el proceso educativo (Yong y Bedoya, 2016).

Un tutor virtual debe asumir tres roles en los procesos de formación de sus estudiantes: el rol pedagógico-social, gerencial-organizativo y técnico. El rol pedagógico-social se refiere a la creación del conocimiento y de ambientes de aprendizaje colectivos. Los tutores virtuales crean oportunidades para que los participantes se conozcan; promueven la interacción respetuosa entre los estudiantes e interactúan con cada uno de ellos. El rol gerencial-organizativo implica definir objetivos de aprendizaje, diseñar actividades, asesorar a los estudiantes, clarificar las reglas y las normas del proceso, y motivar la participación de cada uno de ellos. Y a partir del rol técnico se ofrecen orientaciones sobre la manera como se deben resolver los problemas técnicos (McPherson \& Nunes, 2004; Rodríguez y Guerrero, 2019). Estos tres roles se complementan y articulan entre sí, y favorecen la permanencia de los estudiantes en los procesos de formación. En esta misma línea, Youde (2016) reconoce algunos atributos en los tutores virtuales. Ellos fortalecen las habilidades en sus estudiantes, propician espacios de conversación, resuelven conflictos, lideran procesos y se constituyen en un referente para ellos.

En conclusión, el tutor virtual es un facilitador del aprendizaje -pues las tecnologías por sí solas no tienen efectos en la formación de los sujetos-; además, es una compañía y guía para los estudiantes. El tutor virtual planea -piensa y reflexiona-su acción educativa de manera sistemática y planificada para seguir de cerca el proceso de cada uno de sus estudiantes. A su vez, se repiensa constantemente, en tanto sus acciones no atienden a formas rígidas y fijas, sino que todo el tiempo se le demanda una posición reflexiva frente al uso de los entornos virtuales de aprendizaje, y a los roles que asumen los estudiantes y los maestros en estos escenarios. 


\section{Método}

En atención al fenómeno abordado en este estudio, asociado con la enseñanza virtual en el contexto de la cultura académica universitaria, se pretendió favorecer la generación de conocimiento vinculado al campo de la educación virtual, a partir de elementos conceptuales, metodológicos y técnicos para el fortalecimiento y transformación de las prácticas de enseñanza de los profesores universitarios en escenarios virtuales. De acuerdo con la naturaleza de este propósito, de carácter comprensivo, la elección metodológica atendió a un enfoque cualitativo, en tanto se buscó comprender, describir y construir perspectivas teóricas desde las cuales se apunta al campo de conocimiento que constituye la educación virtual; y se pretendió obtener cierta flexibilidad para la interpretación y comprensión del fenómeno estudiado desde diferentes puntos de vista. En términos de Hernández et al. (2014): "examinar la forma en que los individuos perciben y experimentan los fenómenos que los rodean, profundizando en sus puntos de vista, interpretaciones y significados" (p. 358).

El marco interpretativo que se utilizó es el que provee el diseño de teoría fundamentada, entendida como la construcción de teoría sustantiva, derivada del proceso sistemático de recopilación, categorización, análisis y comparación de los datos (Strauss y Corbin, 2002). Este diseño metodológico sistemático consiste en, inicialmente, la recolección de los datos, y seguidamente los procesos de codificación abierta, codificación axial, codificación selectiva, para, finalmente, visualizar la emergencia teórica.

Desde esta perspectiva, las técnicas que se utilizaron para ello fueron:

Análisis documental, que se refiere a documentos y/o materiales que ayudan a comprender el objeto de estudio y "le sirven al investigador para dar a conocer los antecedentes de un ambiente, así como las vivencias o situaciones que se producen en él” (Hernández et al., 2014, p. 415). En este caso, los documentos corresponden a estudios previos asociados con programas de formación para tutores virtuales y sus funciones, para la configuración del estado del arte.

La entrevista semiestructurada, enfocada en las siguientes preguntas asociadas con el rol del tutor en el espacio de formación: ¿qué aporta desde lo conceptual, metodológico, técnico y socioafectivo, contar con el acompañamiento de un tutor virtual?; ¿considera que la forma en la 
La enseñanza virtual | Revista Virtual
Universidad Católica del Norte, $65,31-65$

ISSN: 0124-5821 (En línea)

cual se abordaron las temáticas fue apropiada (rol del dinamizador)?; ¿cuáles considera deben ser las funciones de un tutor virtual que apoya procesos de formación de maestros?; ¿de qué manera las estrategias de acompañamiento, comunicación e interacción favorecieron o no la apropiación conceptual y el aprendizaje (rol del dinamizador)?; explique cuáles de las estrategias evaluativas propuestas en el diplomado han contribuido a evidenciar la apropiación de los procesos y conceptos abordados en el diplomado y cuáles no; ¿qué papel han jugado sus pares académicos en su proceso formativo?; ¿cómo ha sido su experiencia con la plataforma Moodle, en relación con los criterios de acceso, navegabilidad e interactividad?; ¿qué asuntos considera que podrían ajustarse, en términos conceptuales, metodológicos, socioafectivos y técnicos, antes de ofertar el diplomado a otros profesores?; ¿qué valoración hace de la duración del diplomado, las actividades sincrónicas, y el trabajo autónomo propuesto?

Y, la observación participante centrada en la mediación del tutor virtual. Se utilizó para ello una matriz que contempló los siguientes aspectos: la planificación del acompañamiento (sincrónico y asincrónico) a los participantes del diplomado; las principales acciones que desarrolla antes, durante y después de los encuentros sincrónicos (acompañamiento que realiza de orden conceptual, metodológico, técnico y socioafectivo); el aprendizaje autónomo como un elemento que favorece o no los procesos de acompañamiento; acciones que facilitan la construcción y deconstrucción de aprendizajes de los participantes; la construcción colectiva de aprendizajes desde la actividad formativa; estrategias de seguimiento a las actividades que desarrollan los participantes; y diferencias en el acompañamiento a los participantes, teniendo en cuenta las áreas de formación a las que pertenecen (ciencias sociales, ciencias básicas y ciencias de la salud).

A partir del diseño de teoría fundamentada que orienta este estudio, la ruta metodológica de la investigación se desarrolló en las siguientes fases:

La primera fue la fase de exploración teórica y diseño de la propuesta de formación, donde se configuró un estado del arte a partir de la revisión y análisis de documentos sobre programas de formación para tutores virtuales, y se identificaron y describieron las funciones de un tutor virtual. Esta actividad inicial dio lugar a la emergencia de los componentes conceptuales, metodológicos, socioafectivos y técnicos que constituyeron la estructura y desarrollo de los contenidos de la propuesta de formación. Dicha propuesta fungió como el escenario de indagación que permitió 
La enseñanza

virtual
La enseñanza virtual | Revista Virtual Universidad Católica del Norte, 65, 31-65

ISSN: 0124-5821 (En línea)

representar los elementos conceptuales, metodológicos, socioafectivos y técnicos, orientados al fortalecimiento y transformación de las prácticas de enseñanza de docentes universitarios. Esto, en el marco del enfoque cualitativo, posibilitó el reconocimiento de las percepciones de los maestros participantes.

La propuesta de formación estuvo expresada en un diplomado de formación continua, a partir del cual se diseñaron contenidos, actividades, materiales y dinámicas de evaluación dispuestos en un aula virtual, soportada en la plataforma Moodle. La estructura curricular estuvo constituida por seis módulos: la educación virtual una apuesta colaborativa; enseñar y aprender en la virtualidad; principios didácticos para la formación virtual; herramientas, recursos y contenidos educativos para la enseñanza virtual; gestión de la enseñanza y el aprendizaje en la virtualidad; evaluar para aprender en el contexto de la virtualidad.

La segunda fase consistió en la implementación de la propuesta de formación (diplomado), realizada con un grupo de veintidós profesores de diferentes áreas de conocimiento (ciencias sociales, ciencias básicas y ciencias de la salud) de la Universidad de Antioquia, interesados en fortalecer y transformar sus prácticas de enseñanza en la virtualidad, atendiendo a los contextos, prácticas y comunidades académicas de las cuales forman parte. En concordancia con lo planteado, se recolectaron los datos mediante la entrevista semiestructurada, aplicada a 9 de los profesores universitarios que participaron en este proceso; y la observación participante, mediante dos informes realizados por los tutores que orientaron el diplomado, diligenciados en el intermedio del este, específicamente 2 meses después de iniciar el proceso, y al final este.

La última fase estuvo enfocada en el proceso de análisis de los datos, a partir del cual emergieron los principales hallazgos en relación con la enseñanza en el contexto de la cultura académica universitaria en entornos virtuales, identificando los procesos de acompañamiento del tutor virtual desde un enfoque conceptual, metodológico y socioafectivo. Este proceso se llevó a cabo atendiendo a la siguiente secuencia, a partir de los planteamientos de Strauss y Corbin (2002): organización de los documentos en el software Atlas.ti; codificación abierta donde se ubican las correspondientes citas y códigos; codificación axial, para la organización de grupos de códigos, memos, grupos de memos y redes; y codificación selectiva, para establecer relaciones entre el enfoque analítico de la ruta y las experiencias de los participantes. Como producto del proceso de codificación abierta y axial, realizado a partir del análisis de las entrevistas a los profesores 
universitarios, emergieron conceptos relacionados con la enseñanza en entornos virtuales que implican acciones desde lo socioafectivo, lo pedagógico y lo metodológico.

\section{Resultados}

El proceso de análisis inició con la categorización abierta de los datos obtenidos en la matriz de observación y las entrevistas aplicadas, a partir de lo cual se derivaron los esquemas categoriales axiales que sintetizan los principales hallazgos. Seguidamente, se presenta el esquema teórico final, resultante del proceso de categorización selectiva.

Atendiendo a esta estructura, en la Tabla 1 se relacionan las categorías abiertas que emergieron de los datos, con algunos ejemplos de las citas (expresiones, de los docentes, tomadas de las entrevistas y la observación) que dieron lugar a las categorías axiales y a los esquemas que se construyeron para identificar y describir las relaciones.

\section{Tabla 1}

Categorías abiertas y ejemplos de relaciones entre citas y categorías axiales derivadas

\begin{tabular}{|c|c|c|}
\hline $\begin{array}{c}\text { Categorías } \\
\text { abiertas }\end{array}$ & Ejemplos de citas & Categorías axiales \\
\hline \multirow{4}{*}{$\begin{array}{l}\text { Características } \\
\text { del tutor }\end{array}$} & $\begin{array}{l}\text { "El profe fue muy claro siempre con todas las orientaciones } \\
\text { también pues como en el manejo de los temas y todo eso } \\
\text { pues bien no, creo que fue muy oportuno contar con ese } \\
\text { espacio de asesorías creo que eso fue muy valioso en el } \\
\text { diplomado lo que te decía" }\end{array}$ & $\begin{array}{c}\text { Acompañamiento y } \\
\text { guía }\end{array}$ \\
\hline & $\begin{array}{l}\text { "El tutor debe de alguna manera tratar de humanizar ese } \\
\text { vínculo entre el estudiante y el curso" }\end{array}$ & $\begin{array}{l}\text { Humanos y } \\
\text { respetuosos }\end{array}$ \\
\hline & $\begin{array}{l}\text { "Que tenga presencia, que esté ahí, que esté dispuesto a } \\
\text { resolver dudas, esa cantidad de dudas que se van } \\
\text { presentando que no solamente tiene que ver con la parte del } \\
\text { contenido, sino que se pueden surgir muchas cosas porque a } \\
\text { la final pienso que es eso, es la persona detrás del equipo } \\
\text { que está ahí, pero que puede escuchar muchas de las } \\
\text { inquietudes que uno pueda tener al respecto, angustias que } \\
\text { le pueda generar el trabajar en esto, y pienso que es } \\
\text { importante esa formación de tutores virtuales" }\end{array}$ & $\begin{array}{l}\text { Disponibilidad y } \\
\quad \text { escucha } \\
\text { Acompañamiento y } \\
\text { guía }\end{array}$ \\
\hline & $\begin{array}{l}\text { "[la tutora] es organizada y sistemática, y siempre es muy } \\
\text { atenta a las necesidades que todos tuvieron y entonces en } \\
\text { todas las clases y en todas las sesiones [sincrónicas] trataba }\end{array}$ & $\begin{array}{l}\text { Organizados y } \\
\text { sistemáticos }\end{array}$ \\
\hline
\end{tabular}


de generar un espacio de confianza para que todos participen

y planteen allí las inquietudes generadas en el curso"

\begin{tabular}{|c|c|c|}
\hline \multirow{3}{*}{$\begin{array}{l}\text { Conocimiento } \\
\text { pedagógico } \\
\text { didáctico del } \\
\text { tutor }\end{array}$} & $\begin{array}{l}\text { "Utilizaba los insumos de lo que ya habíamos leído o sea, } \\
\text { preguntaba y trataba lo que tenía como de hacerlo" }\end{array}$ & $\begin{array}{l}\text { Incentivan la } \\
\text { profundización de } \\
\text { los contenidos. }\end{array}$ \\
\hline & $\begin{array}{l}\text { "Yo siento como que la construcción de aprendizaje, de } \\
\text { comunidad virtual, hizo parte también de esas } \\
\text { intervenciones porque yo sentía que ella me pensaba, porque } \\
\text { cuando hacíamos las preguntas de retroalimentación yo } \\
\text { decía estaba profe me pensaba" }\end{array}$ & Dominio teórico \\
\hline & $\begin{array}{l}\text { "La profe nos hizo sentir como que eso en todo tiempo } \\
\text { estaba en construcción y en proceso, y que lo que hoy } \\
\text { teníamos podía ser mejorado con un reto, como retarnos a } \\
\text { nosotros mismos y a nuestras posibilidades, entonces yo } \\
\text { creo que denominarlo como reto y no con otro nombre si } \\
\text { tiene como unas implicaciones en las compresiones, al } \\
\text { menos en las expectativas que uno se crea para poder } \\
\text { producir" }\end{array}$ & $\begin{array}{l}\text { Diversifican } \\
\text { estrategias de } \\
\text { enseñanza }\end{array}$ \\
\hline \multirow{4}{*}{$\begin{array}{l}\text { Logros } \\
\text { metodológicos } \\
\text { del tutor }\end{array}$} & $\begin{array}{l}\text { "El proceso de retroalimentación por parte de los tutores fue } \\
\text { un elemento clave para la comprensión de la ruta de } \\
\text { formación, se resalta la pertinencia de los reflejos de los } \\
\text { tutores a lo largo del proceso" }\end{array}$ & $\begin{array}{l}\text { Retroalimentación } \\
\text { Asesorías } \\
\text { pertinentes }\end{array}$ \\
\hline & $\begin{array}{l}\text { "Aparte de generar ese espacio de diálogo a partir de las } \\
\text { experiencias de cómo nos estaba yendo y demás, guiaba y } \\
\text { orientaba ese camino [para] uno no perderse, por asuntos tan } \\
\text { simples como que algunos profes decían: no encuentro este } \\
\text { botón, eso está muy raro en la plataforma, yo no encuentro } \\
\text { este texto cosas así de simples como también cosas más de } \\
\text { dificultades individuales" }\end{array}$ & $\begin{array}{l}\text { Asesorías } \\
\text { pertinentes }\end{array}$ \\
\hline & $\begin{array}{l}\text { "En los espacios de asesoría se brindaron orientaciones } \\
\text { claras incentivando siempre a la profundización de los } \\
\text { contenidos" }\end{array}$ & $\begin{array}{l}\text { Asesorías } \\
\text { pertinentes }\end{array}$ \\
\hline & $\begin{array}{l}\text { "El proceso de retroalimentación por parte de los tutores fue } \\
\text { un elemento clave para la comprensión de la ruta de } \\
\text { formación, se resalta la pertinencia de los reflejos de los } \\
\text { tutores a lo largo del proceso" }\end{array}$ & Retroalimentación \\
\hline
\end{tabular}

Nota: Elaboración propia.

Por otra parte, la Figura 1 representa el primer esquema axial asociado con las características del tutor (categoría abierta). En el marco del análisis de las relaciones identificadas (categorización selectiva), a partir de los relatos de los participantes y profesores tutores que hicieron parte de la investigación, se determina que la acción tutorial está mediada en gran medida 
por asuntos como la motivación, el acompañamiento, el respeto, y la escucha, los cuales se pueden asociar con una perspectiva socio afectiva del sujeto.

\section{Figura 1}

\section{Características del tutor}

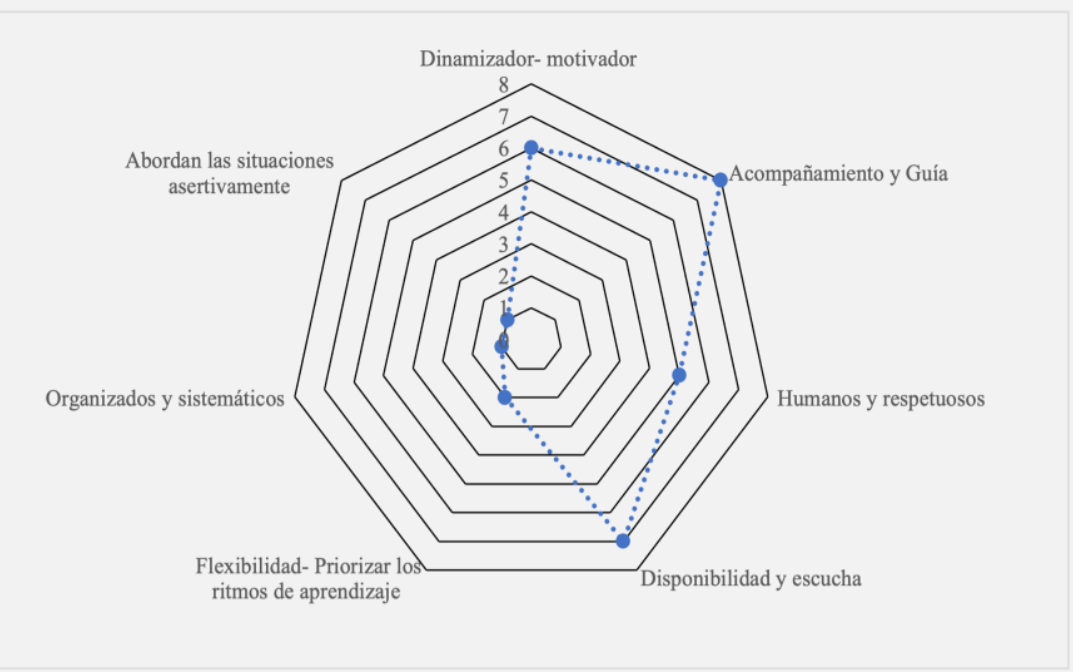

Nota: elaboración propia.

Al respecto, los participantes expresan sobre el tutor que "debe de alguna manera tratar de humanizar ese vínculo entre el estudiante y el curso". Y que:

Tenga presencia, que esté ahí, que esté dispuesto a resolver dudas, esa cantidad de dudas que se van presentando que no solamente tiene que ver con la parte del contenido, sino que se pueden surgir muchas cosas porque a la final pienso que es eso, es la persona detrás del equipo que está ahí, pero que puede escuchar muchas de las inquietudes que uno pueda tener al respecto, angustias que le pueda generar el trabajar en esto, y pienso que es importante esa formación de tutores virtuales.

Así, desde un enfoque socioafectivo de la enseñanza virtual, las relaciones pedagógicas ocupan un lugar preponderante; esto es propiciar un vínculo social que permita a los participantes implicarse en el proceso de aprendizaje y procurar el reconocimiento del otro como parte del proceso formativo. Aunque otras características asociadas con la organización y la flexibilidad emergen y son importantes, los participantes ponen el acento en aquellas que favorecen la distancia transaccional entre profesor y estudiante. 


\section{Figura 2}

Conocimiento pedagógico didáctico del tutor

Nota: elaboración propia.

El segundo esquema categorial, representado en la figura 2, da cuenta de los elementos que emergieron en relación con la formación del tutor. Para los participantes es importante "repensarse este nivel formativo a partir de la virtualidad". Es decir, una formación que debe dar cuenta de un dominio de los contenidos, las estrategias de enseñanza y la evaluación en el marco de una educación que se desarrolla en ambientes virtuales. Al respecto, es importante señalar como categoría selectiva: la identificación de tales conocimientos, como asuntos que se ven afectados por el ciberespacio, y que establecen retos al docente, en relación con lo que ha significado la pedagogía y la educación a lo largo de la historia. Así lo expresa una participante: "Vale la pena presentar esas otras variaciones de quien también dice que aquí hay unos modelos que pueden afectar condiciones que ya se han ganado en el ejercicio de la pedagogía". Un cuestionamiento que emerge de estas reflexiones es si los referentes teóricos y metodológicos asociados con la pedagogía y la didáctica se mantienen estables, o son necesarios nuevos enfoques que consideren la manera en la que el tutor se desempeña en entornos virtuales. 


\section{Figura 3}

Logros metodológicos del tutor

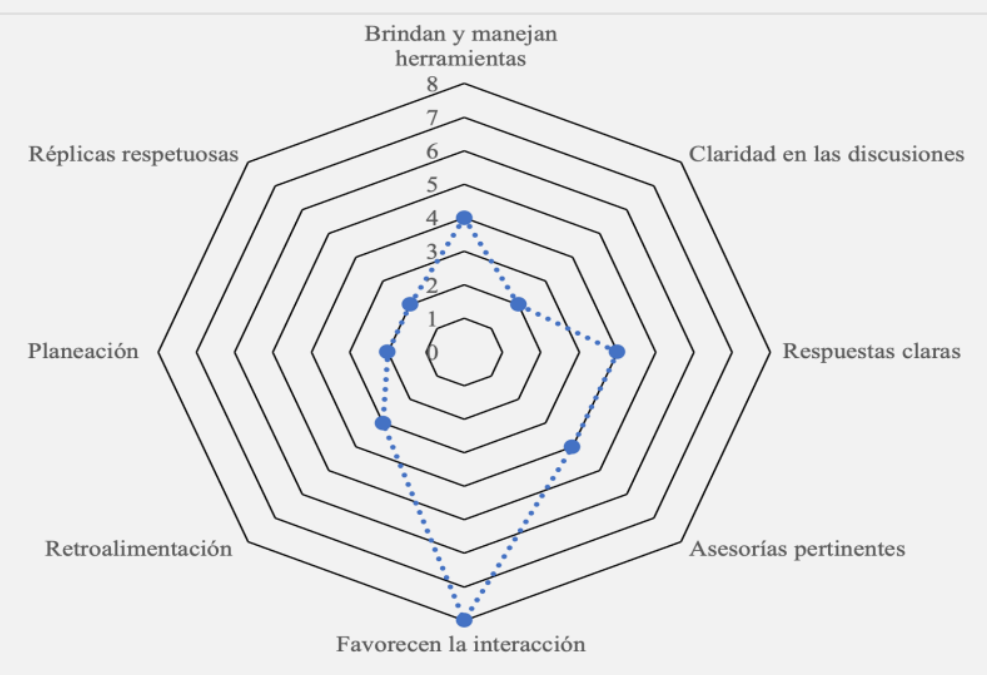

Nota: elaboración propia.

El tercer esquema de categorías emergentes (ver Figura 3) da cuenta de asuntos de orden metodológico en la enseñanza virtual, dado que las respuestas de los participantes estuvieron centradas en destacar la importancia de favorecer las interacciones en línea, a través de una comunicación clara, asertiva en los encuentros sincrónicos y asincrónicos; también, en ubicar la planificación de la acción didáctica como un asunto que coadyuva la articulación entre la teoría pedagógica, la didáctica y la evaluación, en pro de una relación pedagógica centrada tanto en el tutor como en los participantes. Así fue expresado a través de las conversaciones:

[la tutora] es organizada y sistemática, y siempre es muy atenta a las necesidades que todos tuvieron y entonces en todas las clases y en todas las sesiones [sincrónicas] trataba de generar un espacio de confianza para que todos participen y planteen allí las inquietudes generadas en el curso.

Yo siento que la construcción de aprendizaje, de comunidad virtual, hizo parte también de esas intervenciones porque yo sentía que ella [la tutora] me pensaba, porque cuando hacíamos las preguntas de retroalimentación, (...) lo que yo hago en las diferentes plataformas, me sentía pensada por ella, y me sentía comentada en las intervenciones eso fue muy importante. 
Aparte de generar ese espacio de diálogo a partir de las experiencias de cómo nos estaba yendo y demás, guiaba y orientaba ese camino [para] uno no perderse, por asuntos tan simples como que algunos profes decían: no encuentro este botón, eso está muy raro en la plataforma, yo no encuentro este texto cosas así de simples como también cosas más de dificultades individuales.

Teóricamente emerge, a partir de lo anterior, un concepto que está asociado con lo que significa la planificación de la enseñanza virtual, enfocada en la conformación de comunidad de aprendizaje y en la presencia docente, representada en ese "estar alli" en medio de una perspectiva dialógica de la enseñanza virtual para favorecer la interacción en una doble vía: profesor y estudiante.

\section{Figura 4}

Esquema teórico resultante del proceso de codificación selectiva

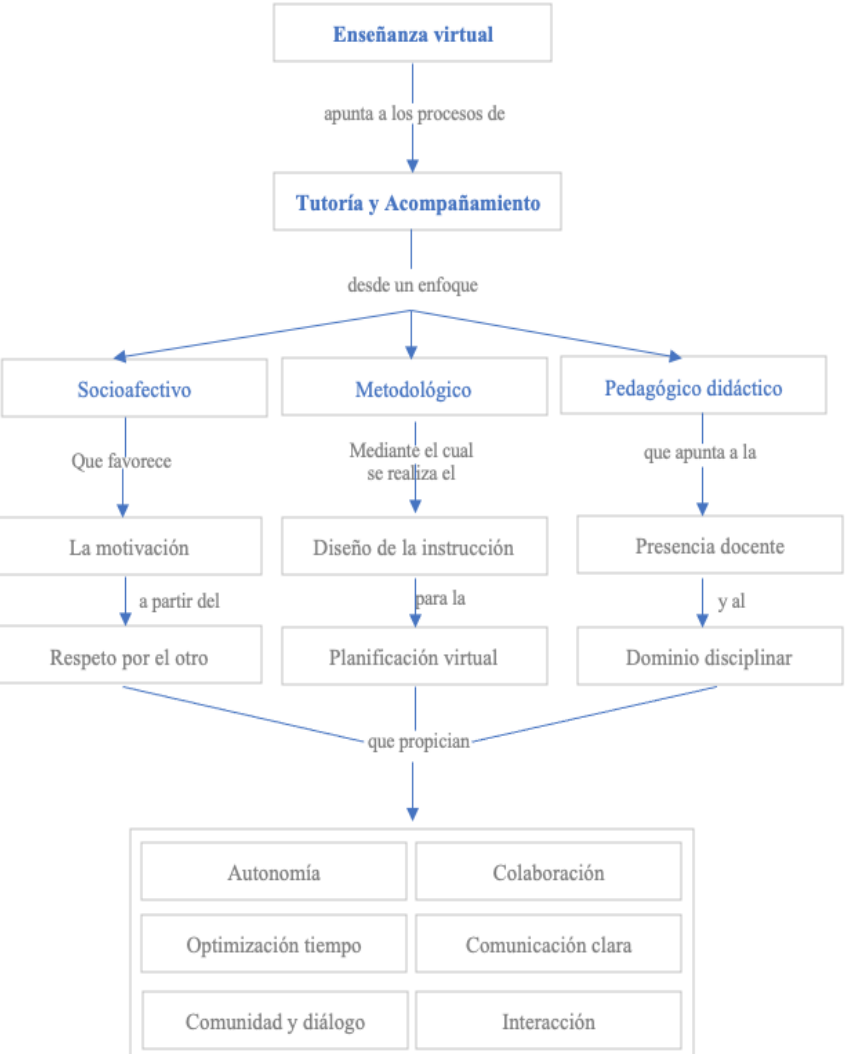

Nota: elaboración propia. 
En el esquema teórico emergente, representado en la figura 4, derivado del proceso de categorización selectiva, se lograron identificar tres enfoques de la enseñanza virtual que permiten el acompañamiento tutorial: (1) el socioafectivo, relacionado con las estrategias que utiliza el tutor para motivar a los estudiantes a partir del respeto por el otro, propiciado prácticas de colaboración, autonomía, comunicación e interacción, orientadas a la consecución de los resultados de aprendizaje en el marco de los procesos formativos; (2) metodológico, el cual se concreta mediante la realización de la planificación de la acción didáctica para la virtualidad; y (3) el pedagógico didáctico, enfocado hacía la presencia docente y el dominio disciplinar desde la enseñanza, permitiendo la consolidación de comunidades, de forma clara y dialógica.

Estos tres enfoques sitúan en el radar otros conceptos que emergen de la relación entre las percepciones de los participantes y algunas teorías subyacentes. A continuación, se presenta la discusión de los resultados, en relación con cada uno de los conceptos que se derivan de los tres enfoques identificados.

\section{Discusión}

Considerando que los propósitos y preguntas que orientaron este estudio se enfocan en la enseñanza virtual, específicamente en asuntos como la formación de tutores para enfrentar la enseñanza y el aprendizaje en el contexto de la virtualidad, y sus funciones y roles en la consecución de los objetivos de aprendizaje, en esta sección se tejen relaciones cualitativas, las cuales proyectan un camino sobre el cual se pueden desarrollar a futuro nuevas propuestas para apoyar la formación de profesores para la enseñanza virtual en el contexto de la cultura académica universitaria.

\section{Conceptos asociados con un enfoque socioafectivo de la enseñanza virtual}

Para los participantes del diplomado, el rol motivador del tutor tiene un lugar preponderante, seguido de su capacidad de acompañar y guiar en el proceso de aprendizaje. Estos hallazgos están asociados con los planteamientos de la autora Gilly Salmon (2013), quien en su 
modelo e-moderating establece cinco etapas para desarrollar habilidades en los tutores, relacionadas con animar, gestionar y moderar con éxito una comunidad de aprendizaje: Acceso y motivación, socialización en línea, intercambio de información, construcción de conocimiento, y desarrollo. Todas ellas están encaminadas a las acciones del tutor cuando el participante accede y participa en un entorno de formación online: ayudar a los participantes con los problemas técnicos y generar acciones de motivación que permitan persuadir al participante sobre el tiempo que debe invertir en el desarrollo de las actividades y su participación en la generación de una comunidad de aprendizaje.

Por otra parte, este énfasis en las características socioafectivas del tutor en un entorno virtual coincide con las ideas planteadas por Badilla \& Meza (2015), quienes, a partir de un estudio realizado para la constitución de un modelo pedagógico para la enseñanza en Mundos Virtuales Inmersivos, encontraron que los entornos virtuales ofrecen un espacio intelectual y tecnológico desafiante y motivador para los participantes. Esto, en la medida en que las habilidades de enseñanza se fortalecen en el marco de sistemas de aprendizajes basados en la simulación y la colaboración. Para Badilla \& Meza (2015), las dificultades técnicas y de usabilidad de los escenarios formativos quedan en un segundo plano, pues son resueltas con facilidad y tranquilidad en el marco de la comunidad de aprendizaje.

\section{Conceptos asociados con un enfoque pedagógico didáctico de la enseñanza virtual}

Los participantes señalaron que el dominio disciplinar del tutor, la profundización en los contenidos y la evaluación son elementos imprescindibles cuando pensamos en el rol tutorial o en la enseñanza virtual. En la investigación se identificaron tres conceptos: presencia docente, aprendizaje en comunidad y colaborativo, y aprendizaje significativo, los cuales se asocian con estos elementos y permiten definir algunas características a considerar para pensar la formación de tutores virtuales. 
La enseñanza

virtual
La enseñanza virtual | Revista Virtual

Universidad Católica del Norte, 65, 31-65

ISSN: 0124-5821 (En línea)

\section{Presencia docente}

El acompañamiento en la relación docente-estudiante se erige como uno de los elementos más importantes de la enseñanza en la modalidad virtual, ya que ello implica, además del dominio de las e-actividades, favorecer el intercambio de saberes, el diálogo y la puesta en marcha de procesos de comunicación requeridos para dichas interacciones. Así mismo, el acompañamiento se puede dar desde diferentes modalidades: acompañamiento personalizado, individualizado, a grupos focales; concebidos como parte complementaria del currículo y con la intención de apoyar los contenidos y objetivos de los cursos. En esta medida, el acompañamiento por parte de los docentes se centra en el apoyo al trayecto académico de los estudiantes. Sin embargo, las tutorías y el acompañamiento en modalidad virtual no se centran únicamente en el recorrido académico de los estudiantes, sino que contemplan, adicionalmente, asuntos asociados con procesos metacognitivos, donde se reconocen formas y métodos de aprendizaje, apropiación y autorregulación del conocimiento. Igualmente, las tutorías también hacen énfasis en situaciones asociadas con aspectos sociales, emocionales y afectivos que condicionan la permanencia o la deserción de los estudiantes.

Aunado a lo anterior, y a partir de la incorporación de las TIC en contextos educativos, surgen nuevos retos vinculados a la tutoría virtual, ya que la consolidación de entornos virtuales de aprendizaje, con enfoques metodológicos no tradicionales, exigen al docente pensar otras formas de acompañamiento, articuladas a nuevas herramientas y estrategias didácticas que posibilitan el reconocimiento de necesidades, potencialidades y competencias de sus estudiantes para la apropiación y fortalecimiento del conocimiento en diferentes dimensiones y aspectos de la vida social, académica y personal. Por esta razón, la presencia docente demanda habilidades que no están basadas en una relación única y objetiva con el saber disciplinar, sino que, en simultáneo, el tutor virtual hace las veces de facilitador, organizador e integrador de ese conocimiento, de la comunicación e interacción que implican los escenarios virtuales, y, en esa medida, del reconocimiento intersubjetivo y social de las comunidades de aprendizaje que se tejen en dichos entornos.

Garrison y Anderson (2005) caracterizan el papel del tutor virtual en tres acciones específicas: diseño y organización, facilitar el discurso y enseñanza directa. Para ello, se resalta la 


\section{La enseñanza virtual | Revista Virtual} Universidad Católica del Norte, 65, 31-65

ISSN: 0124-5821 (En línea)

presencia docente del tutor, en tanto orientador de procesos sociales y cognitivos, referidos a la creación de ambientes y escenarios que susciten confianza, autorreconocimiento dentro de una comunidad de aprendizaje, deseo de participación, posturas críticas, generación de interrogantes, diálogos, procesos rigurosos de curaduría del material educativo, entre otros.

En el marco del diplomado en el que se desarrolló esta investigación, la presencia docente fue valorada positivamente por parte de los estudiantes, ya que hubo un reconocimiento de las acciones llevadas a cabo por los tutores, las cuales se asociaron al diseño de la estrategia, acompañamiento pedagógico y organización de los contenidos; así mismo, se percibieron acciones orientadas a facilitar el discurso; y, finalmente, la enseñanza directa para la construcción del conocimiento. Así lo expresaron algunos participantes en las entrevistas realizadas: "Constantemente brindaban herramientas y estrategias diversificando las estrategias de enseñanza"; "Generaron un clima de clase donde había confianza para participar".

En este sentido, el acompañamiento tutorial en la virtualidad constituye una apuesta educativa, en la que los estudiantes superan la condición de extranjeros para ingresar y explorar una cultura académica mediada por el uso y la implementación de las TIC, donde emergen otras formas de ser y de relacionarse con el conocimiento, consigo mismos y con los otros. Atendiendo a ello, y retomando a Ariza y Ocampo (2004), la tutoría virtual aporta al desarrollo personal y subjetivo, ya que se movilizan saberes de "índole intelectual, afectivo, social, académico, profesional e institucional" (p. 34). Por ello, la figura del docente tradicional se transforma en una presencia docente dinámica que atiende a una mirada social de la pedagogía, basada en el reconocimiento de los actores, las prácticas y la creación conjunta del conocimiento; atendiendo a los procesos de aprendizaje diferenciados.

Por su parte, y con el fin de caracterizar la tutoría virtual, Toledo (2017) expone una tipología de la tutoría virtual, en la cual se relacionan las características concretas del tutor, en función del aprendizaje de los estudiantes y el tipo de relación pedagógica que se desee establecer. A continuación, se señalan algunas acciones que se pueden derivar de dicha clasificación, y que a su vez estuvieron presentes en el diplomado:

En primera instancia, instrucción clara y precisa por parte del tutor para la realización de actividades, así como del funcionamiento, características y cualidades del material didáctico y técnico del entorno donde se desarrollan las mismas. Esta acción es contemplada por algunos 
participantes del diplomado, quienes expresaron en la entrevista que: "En los espacios de asesoría se brindaron orientaciones claras incentivando siempre a la profundización de los contenidos".

En segunda instancia, el establecimiento de canales de comunicación que posibiliten un diálogo oportuno, asertivo y respetuoso para crear relaciones de confianza, y en esa medida apoyo ante las dificultades y tropiezos que presenten los estudiantes. Al respecto, una participante manifestó que: "El acompañamiento fue constante y siempre manifestaron disponibilidad"; "Se mostraron como seres humanos cálidos y con gran apertura".

Por último, la realización de procesos de revisión y retroalimentación de los trabajos y tareas que los estudiantes hacen durante el proceso formativo. Acción que da cuenta de una construcción polifónica y crítica del conocimiento, puesto que las creaciones de los estudiantes pueden ser potenciadas por la mirada del tutor y de los demás compañeros.

Lo mencionado anteriormente, revela una presencia docente activa en el diplomado, con diversas cualidades y funciones que posibilitaron la culminación del proyecto educativo con aspectos positivos y relevantes para los procesos de enseñanza-aprendizaje en contextos virtuales. Seoane (2014) define al docente o tutor online como:

La figura docente y profesional que acompaña a un grupo de estudiantes en una parte de su itinerario formativo, garantizando la eficacia del proceso de enseñanza-aprendizaje en todas sus facetas, fomentando la consecución de los objetivos, adquisición de contenidos, competencias y destrezas previstas para la intervención formativa de la que es responsable, en un contexto de aprendizaje colaborativo y activo, y evaluando el grado de cumplimiento de esos objetivos, tanto por parte de los estudiantes como de la propia iniciativa formativa (gestión de la calidad). (p. 429)

En consecuencia, los procesos de acompañamiento tutorial en modalidad virtual requieren de orientación y apoyo para alcanzar objetivos diversos, orientados a la apropiación del conocimiento, al fortalecimiento de competencias cognitivas y comunicativas, así como a la construcción social y crítica del conocimiento. 
La enseñanza

virtual
La enseñanza virtual | Revista Virtual

Universidad Católica del Norte, 65, 31-65

ISSN: 0124-5821 (En línea)

\section{Aprendizaje en comunidad y colaborativo}

Desde los inicios de la humanidad las comunidades o colectivos de aprendizaje han sido una forma de compartir el conocimiento cultural para lograr su supervivencia y ampliar su perspectiva del mundo. Dada su naturaleza social y estructural, las comunidades conforman lo que se ha denominado sistemas sociales de aprendizaje, y definen las competencias que los caracterizan: modos de participación, interacción y conocimiento que se ponen en juego. En la actualidad, las experiencias de formación de comunidades de aprendizaje no solo se circunscriben a lo presencial. Las TIC, y su incorporación en el ámbito social y educativo, han dado paso a la formación de comunidades virtuales de aprendizaje, caracterizadas por el uso del ciberespacio como soporte o plataforma de la interacción y construcción colectiva de conocimientos entre personas.

En esta investigación, los participantes del diplomado pudieron identificar, como estrategia de enseñanza: el trabajo en equipo y en comunidad, evidenciado en la conformación de comunidades de aprendizaje. Así lo expresa una de las participantes: "Resalto mucho el trabajo de equipo, obviamente porque en el equipo uno tiene que aportar desde su saber, desde su iniciativa, desde su capacidad para poder entre todos tener un producto y lograr unas competencias de aprendizaje".

Algunos autores coinciden en definir las comunidades virtuales como aquellas que tienen el interés en el aprendizaje de un contenido, tarea o área de conocimiento (Palloff \& Pratt, 1999; Turoff et al., 1995). De ahí que puedan emerger tantas comunidades como tareas de aprendizaje existan, contextos socio-institucionales e intereses de sus participantes.

Al respecto, algunos estudios realizados sobre procesos de formación en modalidad virtual, para apoyar el desarrollo de competencias relacionadas con la tutoría virtual (Cowan, 2020; Islam et al., 2015; Nortvig et al., 2018; Pineda Báez et al., 2013), dan cuenta de la importancia de contemplar un modelo de formación docente basado en el aprendizaje en comunidad, para producir cambios en los patrones de enseñanza. Estos autores señalan algunos factores clave para lograr un aprendizaje de este tipo: la perspectiva pedagógica en entornos virtuales de aprendizaje; el tiempo para desarrollar ideas y habilidades nuevas; el lugar de los administradores escolares como actores en el cambio pedagógico; el estudiante como agente activo; conceptos como autonomía, trabajo 
La enseñanza virtual | Revista Virtual Universidad Católica del Norte, 65, 31-65

ISSN: 0124-5821 (En línea)

colaborativo, interacción y acompañamiento; la presencia docente; las comunidades virtuales y las interacciones entre estudiantes, docentes y contenidos. De acuerdo con lo anterior, es posible reafirmar las implicaciones relacionadas con el trabajo colectivo, dialógico y compartido, como estrategia que apoya la enseñanza en términos conceptuales, metodológicos, y también evaluativos.

Las experiencias que manifiestan los participantes están asociadas con el concepto de comunidades de aprendizaje delimitadas (Wilson et al., 2004), el cual se deriva de la idea de que las comunidades virtuales pueden ser configuradas desde el contexto institucional, a modo de experiencia escolar concreta o enfocada a una tarea específica.

Este tipo de comunidades está soportado en procesos sociales y de colaboración que tienen su origen en el paradigma del aprendizaje socioconstructivista. De manera específica, en la teoría del aprendizaje colaborativo, desde la cual se puede imaginar una nueva cultura de la comunicación y la participación. Desde la perspectiva de Miranda (2004):

En estas comunidades los participantes más aventajados -expertos- siempre instruyen a los nuevos integrantes -novatos-. Algunas veces los miembros de la comunidad tienen responsabilidades especiales, como resumir las ideas en una reunión, encauzar las discusiones, moderar y preguntar las participaciones, recordar a los participantes las reglas de comportamiento entre otras actividades. (p. 8)

Definitivamente, en una comunidad el estudiante tiene la oportunidad de vivir una experiencia de aprendizaje basada en el conocimiento de los miembros de la comunidad; en el establecimiento de relaciones cercanas que aportan al propósito de aprendizaje; en la idea de aportar, desde los conocimientos propios, a la consecución de los objetivos generales; en la posibilidad de alcanzar los intereses propios y los colectivos. Entre más involucrado o implicado esté el estudiante con la comunidad, más oportunidades de aprendizaje se podrán configurar.

\section{Aprendizaje autónomo}

Otro elemento importante hallado en los resultados de las entrevistas realizadas a los participantes tiene que ver con la autonomía, especialmente con el manejo del tiempo y de las actividades sincrónicas y asincrónicas por parte de los profesores o tutores del diplomado. Así lo 
La enseñanza

virtual
La enseñanza virtual | Revista Virtual Universidad Católica del Norte, 65, 31-65

ISSN: 0124-5821 (En línea)

manifestó una participante en la entrevista: "el trabajo autónomo es muy importante, teníamos los tiempos adecuados para nosotros poder revisar, estudiar, hacer el reto, yo pienso que estuvo bien diseñado".

La perspectiva de independencia o autonomía es concebida como una de las contribuciones teóricas más importantes en el campo de la educación a distancia. Su precursor más importante fue el profesor universitario norteamericano Charles Wedemeyer, para quien la esencia de la educación a distancia está en la independencia del estudiante, lo cual implica la separación del acto de enseñanza, en relación con el aprendizaje, una ruptura en la barrera espacio - tiempo, y el uso de las tecnologías para apoyar el proceso educativo (Galarza, 1996; Simonson, 2014).

Wedemeyer (1971) reconoce algunas características importantes en el desarrollo de su teoría: el estudiante y profesor están separados, la enseñanza y el aprendizaje son mediados por el uso de dispositivos, la individualización caracteriza la enseñanza, el estudiante va a su propio ritmo y produce el aprendizaje por medio de su actividad, se ofrecen diferentes metodologías y formatos a los estudiantes, combina diferentes medios y métodos en el marco del proceso formativo, y la comunicación como factor importante en la relación profesor - estudiante.

En esta perspectiva teórica, la clave del éxito en la educación a distancia, específicamente en la educación virtual, está en el desarrollo de la relación entre estudiante y profesor. De ahí que, para el caso concreto de la estrategia de formación Educar en la virtualidad, una enseñanza que deja huella, el rol del tutor y el manejo de los tiempos, actividades y procesos de acompañamiento haya tenido un lugar preponderante según las consideraciones de los participantes: "El proceso de retroalimentación por parte de los tutores fue un elemento clave para la comprensión de la ruta de formación, se resalta la pertinencia de los reflejos de los tutores a lo largo del proceso"

Resulta importante considerar, en una propuesta de formación virtual, las implicaciones del estudio independiente o autónomo y el manejo de los tiempos asociados con el concepto de distancia transaccional de Moore (1997). El autor propone dos aspectos fundamentales basados en su experiencia como docente universitario: el nivel de autonomía del estudiante y la distancia entre profesor y estudiante. Esta distancia no es sólo una separación geográfica entre profesor y estudiante, sino que corresponde a un concepto pedagógico que "connota la interacción entre el entorno, los individuos y los patrones de comportamiento en una situación" (p. 1). En definitiva, se define como el estado de separación que afecta el proceso de enseñanza y aprendizaje, 
produciendo un espacio psicológico y de comunicación, así como un margen de error potencial, en tal espacio, que puede dar lugar a malentendidos. En el marco de la teoría de la distancia transaccional de Moore, Galarza (1996) expresa lo siguiente:

La estructura de un programa es importante porque debe cubrir todas las posibles interpretaciones incorrectas, dejando abierta la oportunidad para que exista diálogo entre instructor y estudiante, el cual conducirá a las transacciones educativas. Asimismo, sugiere que entre más diálogo y estructura haya en un programa, habrá menos distancia, en el sentido que lo plantea su estudio. De la misma manera, entre menos diálogo y estructura exista en el programa, habrá más distancia presente. (p. 6)

Desde esta perspectiva, en la enseñanza virtual es indispensable considerar los siguientes asuntos: la estructura de los programas de formación, de modo que garanticen una planificación adecuada de las estrategias de comunicación, conceptualización y evaluación; la interacción entre estudiante y profesor, que permita retroalimentaciones asertivas; y la naturaleza y el grado de autonomía del estudiante, lo cual permitirá que haya un equilibrio y dominio entre la dinámica de actividades sincrónicas y asincrónicas. Todo lo anterior, bajo la idea de mantener la mejor distancia posible entre el profesor y el estudiante.

\section{Conceptos asociados con un enfoque metodológico de la enseñanza virtual}

Las respuestas de los participantes sobre este enfoque estuvieron centradas principalmente en elementos tales como: el manejo de las herramientas, claridad en la comunicación, las interacciones en línea y una oportuna retroalimentación. En esta medida, es posible establecer una relación directa entre estos elementos y el sentido e importancia que tienen los procesos de planificación en la enseñanza virtual.

La planificación de la enseñanza virtual se enmarca, inicialmente, en la teoría del estudio independiente y en el diseño de la instrucción, propuestas por la perspectiva pedagógica conductista; razón por la cual esta se constituye como un modelo de referencia relevante para la educación a distancia, especialmente para la generación centrada en el uso de internet, desde su dimensión educativa. Desde esta perspectiva pedagógica se busca tecnificar la enseñanza para que sus efectos sean más eficientes y objetivos. Sin embargo, la planificación de la enseñanza virtual 
es afinada y nutrida, posteriormente, por otras perspectivas pedagógicas como el constructivismo y el conectivismo, de donde deviene el potencial de la interactividad y el aprendizaje colaborativo de la educación mediada por la tecnología, y en esa medida, la posibilidad de construir redes y nodos de conocimiento y aprendizaje en constante cambio.

De acuerdo con lo anterior, la teoría del estudio independiente es reconocida como el centro de la educación a distancia; algunos elementos importantes que la definen son la independencia del estudiante; la separación del acto de enseñanza, en relación con el aprendizaje; y el uso de las tecnologías para apoyar el proceso educativo (Galarza, 1996; Simonson, 2014). No obstante, es preciso señalar que, en el principio de autonomía e independencia del estudiante, su relación con el docente no desaparece; por el contrario, se alimenta de nuevas formas y canales de comunicación e interacción, basadas en el diálogo, la cooperación y el acompañamiento en diferentes esferas que integran la construcción del conocimiento: aspectos sociales, cognitivos, didácticos.

En esta línea cobra especial relevancia el concepto de diseño instruccional, el cual "se ocupa de la planeación, la preparación y el diseño de los recursos y ambientes necesarios para que se lleve a cabo la enseñanza y el aprendizaje" (Belloch, 2017, p. 2). Por ello es fundamental que los procesos de enseñanza y aprendizaje estén direccionados por unos objetivos claros que orienten el curso y permitan definir su alcance formativo, dando lugar al desarrollo de rutas de formación, en las cuales se establecen las actividades, tareas y procesos.

Coll et al. (2008) mencionan dos dimensiones propias para la construcción del diseño instruccional: la dimensión tecnológica, la cual considera la selección de herramientas de acuerdo con los propósitos y a la implementación didáctica de estrategias y procesos formativos; y la dimensión pedagógica, que sitúa las prácticas y saberes previos de los participantes en relación con el tema o asunto de trabajo. Así mismo, se centra en el análisis de los objetivos de la formación virtual, la implementación y desarrollo de contenidos articulados al contexto específico de formación, finalidad y secuencialidad de las actividades, que deben pasar por la reflexión del cómo y para qué de las tareas propuestas. Es importante que exista un diálogo entre ambas dimensiones, de manera que se ofrezcan orientaciones y sugerencias claras y precisas sobre el uso de recursos y herramientas tecnológicas, tanto para el desarrollo de las actividades como para la preparación y puesta en marcha de una propuesta de evaluación de los procesos. Así pues, el diseño instruccional 
obedece a criterios de integración tecnológica que se dan en consonancia con el diseño de objetivos didácticos.

En las entrevistas realizadas a los estudiantes del diplomado se encontró que las dimensiones mencionadas del diseño instruccional son consideradas como elementos fundamentales para el desarrollo de los procesos de formación virtual, así como para el cumplimiento de los propósitos del curso. En este sentido, se resalta la coherencia en el diseño, las herramientas tecnológicas y el material didáctico utilizado en el diplomado, lo cual permitió el cumplimiento de los objetivos trazados para el curso en mención. Así mismo, se reconoce un rol activo del tutor, en términos de claridad conceptual, planificación y acompañamiento oportuno, transversalizado por ejercicios de retroalimentación constante. Ello sugiere que, en términos de la planificación del diplomado, se consideró el antes, el durante y el después de cada detalle que intervino en el proceso.

\section{Conclusiones}

El proceso de investigación desarrollado, a partir del cual se pudo construir e implementar el diplomado Educar en la virtualidad, una enseñanza que deja huella generó aportes al campo de estudio de la educación virtual, relacionados con las implicaciones conceptuales, metodológicas y socioafectivas de la enseñanza en el contexto de la cultura académica universitaria en entornos virtuales.

Un primer aporte fue el reconocimiento de elementos de orden teórico y procedimental asociados a la enseñanza y al aprendizaje que se da en el contexto de la virtualidad, y a partir de los cuales se identificó la importancia de que el docente, desde la tutoría, atienda a las características atribuidas al acompañamiento y a las formas de la presencia docente. Dichas formas podrían vincularse con aspectos de orden social, académico y cognitivo, propios de la tutoría virtual, que intervienen en el proceso de aprendizaje, y, por consiguiente, en la permanencia de los estudiantes, en tanto son los docentes quienes promueven, en estos, capacidades para asumir un rol activo en el proceso de formación, desde la autonomía, la autogestión del aprendizaje y la construcción de comunidades de aprendizaje. 
Un segundo aporte se orientó a repensar la planificación del proceso formativo, de modo que reconozca las formas de comunicación e interacción que caracterizan las relaciones sociales que se dan en el ciberespacio; y apunte a la consolidación de entornos de aprendizaje que vinculen conocimientos asociados con el dominio de herramientas, la configuración de materiales educativos, y la conciencia sobre las relaciones pedagógicas que se ponen en juego en la enseñanza virtual.

En esta perspectiva, el rol del docente en el contexto de la educación virtual adquiere un lugar preponderante, es decir se revela que la mediación pedagógica y el interés del docente por los sujetos que se están formando es una condición para cumplir con los propósitos formativos de los cursos. En el marco del proceso formativo desarrollado, los tutores tuvieron un papel relevante a lo largo del desarrollo del diplomado; su rol fue altamente valorado por los participantes, en tanto se sintieron acompañados y motivados a participar en los espacios sincrónicos y asincrónicos. Adicionalmente, coincidieron en que los tutores virtuales tenían dominio pedagógico y didáctico de los temas, les presentaron diversas estrategias de enseñanza y aprendizaje, acogieron sus particularidades y ritmos de trabajo, y generaron un clima de confianza en los diferentes escenarios de formación.

Finalmente, es importante mencionar que, desde la perspectiva del proceso de investigación, queda un escenario propicio para continuar indagando acerca de las prácticas de enseñanza virtual desde un enfoque cuantitativo. Esto implicaría explicar y evaluar la teoría emergente/sustantiva, a partir de las hipótesis que se pueden derivar de la ejecución del proceso formativo. Y, además, ampliar la muestra a un número mayor de docentes interesados en incorporar la perspectiva de la educación virtual en la cultura académica universitaria.

\section{Referencias}

Ariza, G., y Ocampo H. B. (2004). El acompañamiento tutorial como estrategia de la formación personal y profesional: un estudio basado en la experiencia en una institución de educación superior. Revista Universitas Psychologica, 4(1), 31-41. http://www.scielo.org.co/scielo.php?script=sci_arttext\&pid=S1657$\underline{92672005000100005 \& \operatorname{lng}=e n \& \ln g=e s}$ 
Badilla, M. G., \& Meza, S. (2015). A pedagogical model to develop teaching skills. The collaborative learning experience in the Immersive Virtual World TYMMI [Un modelo pedagógico para desarrollar habilidades docentes. La experiencia de aprendizaje colaborativo en el mundo virtual inmersivo TYMMI]. Computers in Human Behavior, 51, 594-603. https://doi.org/10.1016/j.chb.2015.03.016

Belloch, C. (2017). Diseño instruccional. http://www.uv.es/ bellochc/pedagogia/EVA4.pdf

Campisi, S. (2018). ITALO (MyLearning Log): a case study in the use of technology-based resources to foster student engagement and autonomy [ITALO (MyLearning Log): un estudio de caso sobre el uso de recursos basados en la tecnología para fomentar la participación y la autonomía de los estudiantes]. In R. Biasini \& A. Proudfoot (Eds.), Using digital resources to enhance language learning - case studies in Italian (pp. 43-53). Research-publishing.net. https://doi.org/10.14705/rpnet.2018.24.797

Castañeda, L., Gutiérrez Porlán, I., Prendes Espinosa, M. P., y Sánchez Vera, M. (2017). Formación docente para la enseñanza en línea en el contexto de la Formación Profesional. UTE. Revista de Ciències de l'Educació, (2), 29-44. https://revistes.urv.cat/index.php/ute/article/view/1813

Chacón, J. (2018). El Tutor Virtual. Habilidades para un desempeño eficaz. https://bit.ly/3yLvrDR Coll, C., Mauri, T., y Onrubia, J. (2008). Los entornos virtuales de aprendizaje basados en el análisis de casos y la resolución de problemas. En C. Coll y C. Monereo (Eds.), Psicología de la Educación Virtual (pp. 213-232). Morata.

Cowan, P. (2020). He 4I Model for Scaffolding the Professional Development of Experienced Teachers in the Use of Virtual Learning Environments for Classroom Teaching [El modelo 4I para andamiar el desarrollo profesional de maestros experimentados en el uso de entornos virtuales de aprendizaje para la enseñanza en el aula]. Contemporary Issues in Technology and Teacher Education, 13(1), 82-98. https://www.learntechlib.org/primary/p/39332/

Díez-Echavarría, L., Valencia, A., \& Cadavid, L. (2018). Mobile learning on higher educational institutions: how to encourage it? Simulation approach [El aprendizaje móvil en las instituciones de educación superior: ¿cómo fomentarlo? Enfoque de simulación]. Dyna, 85(204), 325-333. https://doi.org/10.15446/dyna.v85n204.63221 
Edel-Navarro, R. (2010). Entornos virtuales de aprendizaje. La contribución de "lo virtual" en la educación. Revista Mexicana de Investigación Educativa, 15(44), 7-15. https://www.redalyc.org/articulo.oa?id=14012513002

Gabarda, V., Colomo, E., y Romero, M. (2019). Metodologías didácticas para el aprendizaje en línea. REIDOCREA, 8(2), 19-36. https://digibug.ugr.es/handle/10481/58493

Galarza, P. (1996). El estudio independiente en una visión sistémica de la educación a distancia. En P. Ávila, y C. Morales (Eds.), Estudio independiente (pp. 21-35). LCE-OEAPROMESUP.

Garrison, D., y Anderson, T. (2005). El e-learning en el siglo XXI: investigación y práctica. Octaedro.

Gerrard, C. (2004). Promoting Best Practice for E-tutoring through Staff Development. University of Paisley.

Gros, B. (2011). Evolución y retos de la educación virtual: construyendo el e-learning del siglo $X X I$. Editorial UOC.

Hernández, R., Fernández, C., y Baptista, P. (2014). Metodología de la Investigación (6 Ed.). McGraw Hill.

Islam, N., Beer, M., \& Slack, F. (2015). E-Learning Challenges Faced by Academics in Higher Education: A Literature Review [Desafíos del aprendizaje electrónico que enfrentan los académicos en la educación superior: una revisión de la literatura]. Journal of Education and Training Studies, 3(5), 102-112. https://doi.org/10.11114/jets.v3i5.947

Llorente, M. C. (2006). El tutor en E-learning: aspectos a tener en cuenta. Revista Electrónica de Tecnología Educativa, (20). https://doi.org/10.21556/edutec.2006.20.517

Martínez, P., Pérez, J., y Martínez, M. (2014). Una (re)visión de la tutoría universitaria: la percepción de estudiantes y tutores de estudios de Grado. Revista de Docencia Universitaria, 12(1), 269-365. https://doi.org/10.4995/redu.2014.6425

McPherson, M., \& Nunes, M. (2004). The role of tutors as an integral part of online learning support [El papel de los tutores como parte integral del apoyo al aprendizaje en línea]. European Journal of Open and Distance Learning. https://eprints.whiterose.ac.uk/999/ 
Miranda, G. (2004). De los ambientes virtuales de aprendizaje a las comunidades de aprendizaje en línea. Revista Digital Universitaria, 5(10), 2-15. http://www.revista.unam.mx/vol.5/num10/art62/nov_art62.pdf

Mishra, S., \& Juwah, C. (2006). Interactions in online discussions: a pedagogical perspective [Interacciones en discusiones en línea: una perspectiva pedagógica]. En C. Juwah, (Ed.), Interactions in online education: implications for theory and practice (pp. 166-180). Routledge.

Moore, M. (1997). Theory of transactional distance [Teoría de la distancia transaccional]. In D. Keegan (Ed.), Theoretical Principles of Distance Education (pp. 22-38). Routledge.

Morado, M., y Ocampo S. (2019). Una experiencia de acompañamiento tecno-pedagógico para la construcción de Entornos Virtuales de Aprendizaje en Educación Superior. Revista Educación, 43(1), 1-26. https://www.redalyc.org/articulo.oa?id=44057415004

Mosquera-González, D., Valencia-Arias, A., Benjumea-Arias, M., y Palacios-Moya, L. (2021). Factores asociados al uso de tecnologías de la información y la comunicación (TIC) en los procesos de aprendizaje de estudiantes de ingeniería. Formación Universitaria, 14(2), 121132. http://dx.doi.org/10.4067/S0718-50062021000200121

Nortvig, A., Petersen, A., \& Balle, S. (2018). A Literature Review of the Factors Influencing ELearning and Blended Learning in Relation to Learning Outcome, Student Satisfaction and Engagement [Una revisión de la literatura de los factores que influyen en el aprendizaje electrónico y el aprendizaje combinado en relación con el resultado del aprendizaje, la satisfacción y el compromiso de los estudiantes]. Electronic Journal of E-Learning, 16(1), 46-55. https://eric.ed.gov/?id=EJ1175336

Pallof, R., \& Pratt, K. (1999). Building learning communities in cyberspace. Effective Strategies for the online classroom. Jossey-Bass.

Pineda Báez, C., Hennig, C., \& Segovia, Y. (2013). Pedagogical models, collaborative work and interaction on online undergraduate programmes in Colombia: Still some way to go [Modelos pedagógicos, trabajo colaborativo e interacción en programas de pregrado en línea en Colombia: aún queda camino por recorrer]. RUSC. Universities and Knowledge Society Journal, 10(2), 187-202. https://doi.org/10.7238/rusc.v10i2.1739

Puerta Gil, C. A., y Mosquera Perea, N. J. (2020). Impacto del microcurso Enseñar en la 
virtualidad: competencias digitales para docentes en AVA. Fundación Universitaria Católica del Norte. Revista Reflexiones y Saberes, (13), 11-22. https://revistavirtual.ucn.edu.co/index.php/RevistaRyS/article/view/1284

Quezada, C. (2017). Las tutorías en la educación superior. Revista de Ciencia, Tecnología e Innovación, 4(3), 376-391. http://45.238.216.13/ojs/index.php/EPISTEME/article/view/439 Rapp, C., \& Gülbahar, Y. (2016). E-Tutor: Scaling Staff Development in the Area of e-Learning Competences [E-Tutor: Ampliación del desarrollo del personal en el área de competencias de e-Learning]. Proceedings of the Third (2016) ACM Conference on Learning @ Scale L@S '16, 327-328. https://doi.org/10.1145/2876034.2893401

Rodríguez, P., y Guerrero, S. (enero-junio, 2019). El tutor virtual, sus funciones y roles como apoyo a la Licenciatura en Bibliotecología y Estudios de la Información en la Modalidad a Distancia del SUAyED-UNAM. Revista Electrónica sobre Tecnología, Educación y Sociedad, 6, (11). https://www.ctes.org.mx/index.php/ctes/article/view/688/807

Runge. A. K., Hincapié, A., Muñoz, D. A., y Ospina, C. (2018). El campo disciplinar y profesional de la pedagogía en Colombia. Fondo Editorial Universidad Católica de Oriente.

Salinas, J. (2005). La gestión de los entornos virtuales de formación. Universidad de Islas Balneares.

Salmon, G. (2013). E-tivities: The key to active online learning [E-actividades: la clave para el aprendizaje activo en línea] (2nd ed.). Routledge.

Segura-Robles, A., y Gallardo-Vigil, M. A. (2013). Entornos virtuales de aprendizaje: nuevos retos educativos. Revista Científica Electrónica de Educación y Comunicación en la Sociedad del Conocimiento, 13(2), 260-272. https://www.ugr.es/ sevimeco/revistaeticanet/numero132/Articulos/Formato/177.pdf

Seoane, P. (2014). Formalización de un modelo de formación online basado en el factor humano y la presencia docente mediante un lenguaje de patrón [Tesis de doctorado]. Universidad de Salamanca.

Silva, J. (2010). El rol del tutor en los entornos virtuales de aprendizaje. Innovación Educativa, 10(52), 13-23. https://www.redalyc.org/pdf/1794/179420763002.pdf

Simonson, M. (2014). Teoría, investigación y educación a distancia. En Educación abierta y a distancia. Editorial UOC. 
Spiegel, A. (2020). Aulas y TIC: viejos y nuevos desafíos pedagógicos. Enseñar entre distancias y presencias. Ministerio de Educación de la Nación.

Strauss, A., y Corbin, J. (2002). Bases de la investigación cualitativa. Técnicas y procedimientos para desarrollar la Teoría Fundamentada. Universidad de Antioquia.

Tejada, J., y Pozos, K. (2018). Nuevos escenarios y competencias digitales docentes: hacia la profesionalización docente con TIC. Revista de Currículum y Formación del Profesorado, 22(1), 25-51. https://recyt.fecyt.es/index.php/profesorado/article/view/63620

Toledo, G. (2017). La virtualidad en la tutoría docente: Una aproximación a su análisis desde la universidad española. Revista Digital de Investigación en Docencia Universitaria, 11(2), 323-342. http://dx.doi.org/10.19083/ridu.11.509

Turoff, M., Harasim, L., Hiltz, S. R., \& Teles, L. (1995). Learning Net-works: A Field Guide to Teaching and Learning Online [Redes de aprendizaje: una guía práctica para la enseñanza y el aprendizaje en línea]. Cambridge, MIT Press.

Valencia-Arias, A., Benjumea Arias, M. L., Morales Zapata, D., Silva Cortés, A., y Betancur Zuluaga, P. (2018). Actitudes de docentes universitarios frente al uso de dispositivos móviles con fines académicos. Revista Mexicana de Investigación Educativa, 23(78), 761790. http://www.scielo.org.mx/pdf/rmie/v23n78/1405-6666-rmie-23-78-761.pdf

Wedemeyer, C. (1971). Independent study. En L. C. Deighton (Ed), The Encyclopedia of Education (pp. 3-30). Macmillan.

Wilson, B., Ludwig-Hardmann, S., Thornam, C., \& Dunlap, J. (2004). Bounded Community: Designing and facilitating learning communities in formal courses [Comunidad limitada: Diseñar y facilitar comunidades de aprendizaje en cursos formales]. International Review of Research in Open and Distance Learning, 5(3). https://doi.org/10.19173/irrodl.v5i3.204

Yong, E., Nagles, N., Mejía, C., y Chaparro, C. E. (2017). Evolución de la educación superior a distancia: desafíos y oportunidades para su gestión. Revista Virtual Universidad Católica del Norte, (50), 81-105. http://www.redalyc.org/articulo.oa?id=194250865006

Yong, E., y Bedoya, D. (2016). De la educación tradicional a la educación mediada por TIC: Los procesos de enseñanza aprendizaje en el siglo XXI. Virtual Educa.

Youde, A. (2016). Tutor Emotional Competences Valued by Learners in a Blended Learning Context [Tutor de las competencias emocionales valoradas por los alumnos en un contexto 
de aprendizaje combinado]. European Journal of Open, Distance and e-Learning, 19(2), 81-97. https://files.eric.ed.gov/fulltext/EJ1138168.pdf 